\title{
Very high-pressure dilatation for undilatable coronary lesions: indications and results with a new dedicated balloon
}

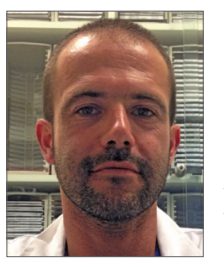

Gioel Gabrio Secco ${ }^{1,2,3}$, MD; Matteo Ghione ${ }^{1}, \mathrm{MD}_{\text {; }}$ Alessio Mattesini ${ }^{1}, \mathrm{MD}$;

Gianni Dall'Ara' ${ }^{1}, \mathrm{MD}$; Liviu Ghilencea ${ }^{1}, \mathrm{MD}$; Kadriye Kilickesmez ${ }^{1}, \mathrm{MD}$;

Giuseppe De Luca ${ }^{2}, \mathrm{MD}, \mathrm{PhD}$; Rossella Fattori ${ }^{4}, \mathrm{MD}$, PhD; Rosario Parisi ${ }^{4}, \mathrm{MD}$;

Paolo Nicola Marino², MD; Alessandro Lupi ${ }^{3}$, MD; Nicolas Foin ${ }^{1}$, MSc;

Carlo Di Mario ${ }^{1 *}, \mathrm{MD}, \mathrm{PhD}, \mathrm{FESC}, \mathrm{FACC}, \mathrm{FRCP}, \mathrm{FSCAI}$

1. NIHR Biomedical Research Unit, Royal Brompton \& Harefield NHS Foundation Trust, London, United Kingdom;

2. Department of Clinical and Experimental Medicine, University of Eastern Piedmont, Novara, Italy; 3. Department of

Interventional Cardiology, "Maggiore della Carità" Hospital, Novara, Italy; 4. San Salvatore Hospital, Pesaro, Italy

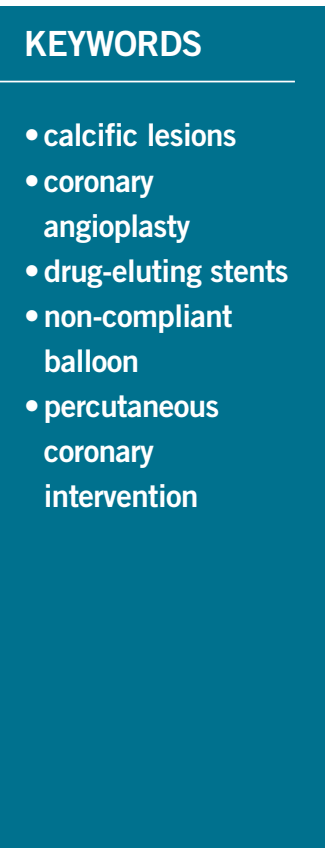

\section{Abstract}

Aims: Calcific coronary lesions impose a rigid obstacle to optimal balloon and stent expansion and the 20 to $30 \mathrm{~atm}$ limit that non-compliant (NC) balloons reach can be insufficient. The aim of our study was to evaluate the safety and efficacy of a new dedicated super high-pressure NC balloon (OPN NC ${ }^{\circledR}$; SIS Medical AG, Winterthur, Switzerland).

Methods and results: We retrospectively evaluated a consecutive series of 91 lesions in which conventional $\mathrm{NC}$ balloons at maximal pressure failed to achieve an adequate post-dilatation luminal gain and were therefore treated with an OPN NC balloon up to $40 \mathrm{~atm}$. Angiographic success was defined as residual angiographic diameter stenosis $<30 \%$. MLD and \%DS were measured at baseline, after NC balloon, OPN NC balloon and stent implantation. Angiographic success was achieved in 84 lesions (92.3\%). All of the remaining lesions received rotational atherectomy with the exception of two cases in which rotational atherectomy was not attempted because of small vessel size and excessive tortuosity. MLD and acute gain were significantly greater and \%DS was significantly lower post OPN NC balloon compared with conventional NC balloon inflation ( $<<0.001$ ). No coronary perforations occurred. No acute or 30-day follow-up MACE was reported.

Conclusions: When conventional NC balloons fail, the new OPN NC dedicated high-pressure balloon provides an effective and safe alternative strategy for the dilatation of resistant coronary lesions.

\footnotetext{
*Corresponding author: Royal Brompton Hospital, Sydney Street, London, SW3 6NP, United Kingdom.

E-mail: c.dimario@rbht.nhs.uk
} 


\section{Abbreviations}

ACT activated clotting time

atm atmosphere

CABG coronary artery bypass graft

CB cutting balloon

DES drug-eluting stent

DS diameter stenosis

ISR in-stent restenosis

IVUS intravascular ultrasound

LVEF left ventricular ejection fraction

MACE major adverse cardiovascular events

MLD minimum lumen diameter

MVD multivessel disease

NC non-compliant

OCT optical coherence tomography

PCI percutaneous coronary intervention

PTCA percutaneous transluminal coronary angioplasty

QCA quantitative coronary angiography

TIMI Thrombolysis In Myocardial Infarction

TVR target vessel revascularisation

ZES zotarolimus-eluting stent

\section{Background}

Heavily resistant coronary lesions remain a challenge in interventional cardiology. Calcification or dense fibrosis of the vessel wall or thick neointimal hyperplasia can create a rigid obstacle to uniform balloon expansion and optimal stent deployment that might result in an increased risk of in-stent restenosis (ISR) and stent thrombosis ${ }^{1}$.

Increasing the pressure beyond the recommended limits during dilatation of resistant lesions often accentuates non-uniform balloon expansion with the consequent overdilatation of the more compliant segments at the lesion edges (so-called "dog-boning" effect) leading to an increased risk of vessel damage ${ }^{2-4}$.

Conventional non-compliant (NC) balloons have more predictable responses and more uniform dilatation than semi-compliant balloons, but even at pressures of 24-30 atm dog-boning also occurs.

A variety of devices and technologies has been developed to overcome these limitations. Cutting balloons (CB), designed to concentrate the dilatation force along three or four blades, are often too bulky to cross truly undilatable lesions and they also may fail to expand at their maximal pressures. Above 16 atm the risk of rupture is quite high, and a ruptured CB might become difficult to reinsert into the guiding catheter. Scoring balloons have a lower profile and accept higher pressure but their efficacy is limited ${ }^{5-9}$. Modification of the vessel wall compliance using rotational atherectomy is certainly the best option, but this technique requires specific expertise in handling a poorly steerable, uncoated 0.010 inch wire and advancing the burr. Excimer laser therapy has been described as an effective last resource in anecdotal cases but a laser is rarely available and perforations are possible. The complexity and the cost of these devices, together with the increased risk of coronary perforation, have hindered their widespread use ${ }^{10}$.
This registry tested the safety and efficacy of a dedicated, super high-pressure non-compliant balloon (OPN NC ${ }^{\circledR}$; SIS Medical AG, Winterthur, Switzerland) in a consecutive series of highly resistant coronary lesions.

\section{Methods \\ LESION SELECTION}

We evaluated 91 consecutive highly resistant coronary lesions in which conventional NC balloons failed to achieve an adequate postdilatation luminal gain. After the failed attempt with the conventional NC balloon, the OPN NC balloon was inflated up to $40 \mathrm{~atm}$ (Figure 1). Other coronary lesions could be treated, when necessary. No exclusion criteria were applied. The OPN balloon is a CE

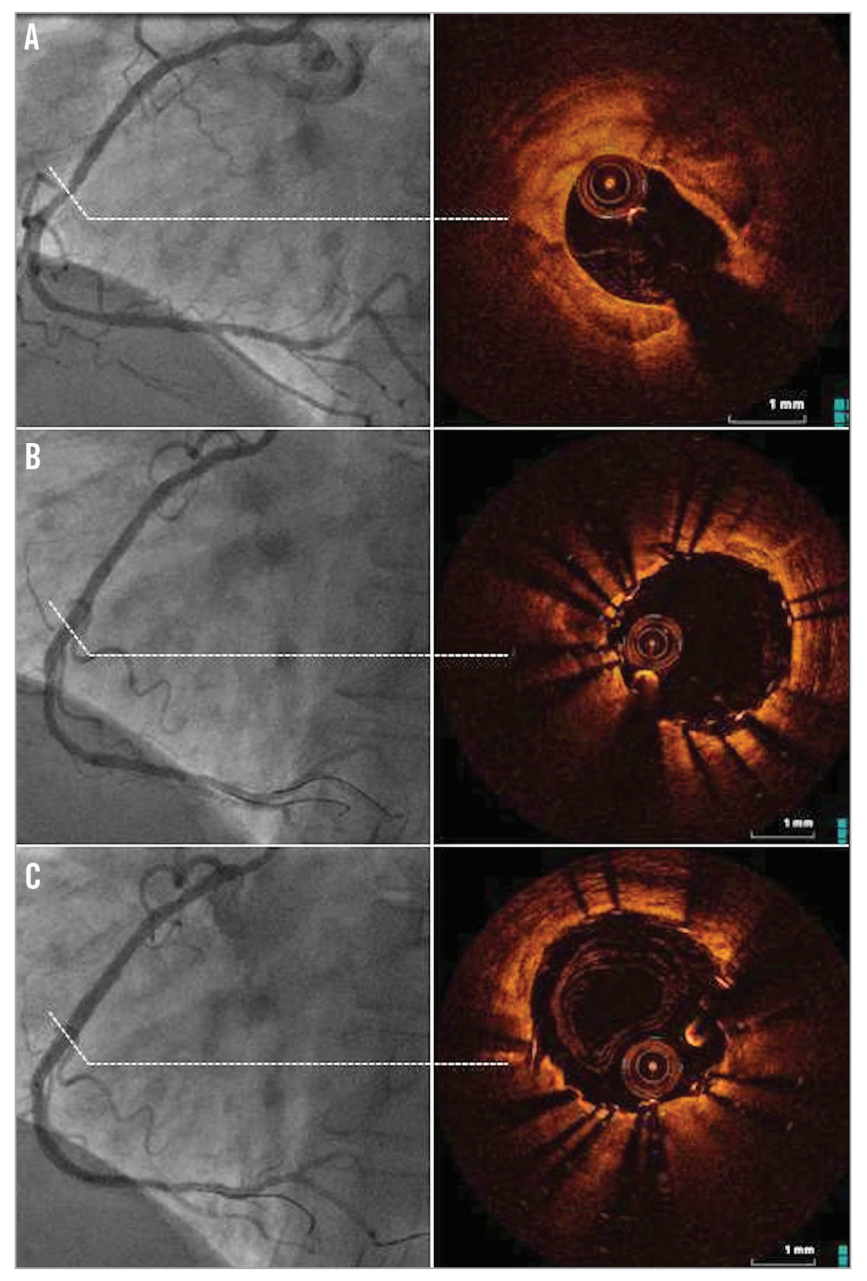

Figure 1. Angiographic and OCT images of a heavily calcified lesion pre-stenting (A), post $3.0 \times 18 \mathrm{~mm}$ ZES implantation followed by an $N C$ balloon inflated at $22 \mathrm{~atm}(B)$, and post-dilatation with a $3.0 \times 15 \mathrm{~mm}$ OPN NC balloon inflated at $38 \mathrm{~atm}(C)$. Please note that the MLD increased to $2.92 \mathrm{~mm}$ (after the NC balloon dilatation) and to $3.18 \mathrm{~mm}$ (after the OPN NC dilatation). In the IVUS/

OCT-guided PCI of the calcified lesion, we found calcium around the vessel contour accounting for at least $>65 \%$ of the plaque, while OCT/IVUS imaging post-OPN NC dilatation shows diffuse vascular injuries following high-pressure inflation but without a significant difference from the conventional NC balloon-treated lesions. 
mark device. Patients signed informed consent for data treatment for scientific purposes, and the study was conducted according to the Declaration of Helsinki.

\section{THE OPN NC BALLOON DEVICE}

The OPN NC super high-pressure balloon (SIS Medical AG) is a rapid exchange percutaneous transluminal coronary angioplasty (PTCA) catheter compatible with 0.014 " coronary wires. The most distinctive feature of the OPN NC balloon is the presence of proprietary twin-layer balloon technology, which permits the use of very high-pressure inflations and ensures uniform expansion over a wide range of pressures (Figure 2). The balloon is highly non-compliant with a nominal pressure of $10 \mathrm{~atm}$ and a rated burst pressure of $35 \mathrm{~atm}$ (Table 1). Each balloon is factory tested at $45 \mathrm{~atm}$. The balloon diameters currently available cover a range from $1.5 \mathrm{~mm}$ up to $4.0 \mathrm{~mm}$ with $1 / 2 \mathrm{~mm}$ intervals. Lengths are 10,15 and $20 \mathrm{~mm}$. The commercial name OPN comes from an abbreviation of op(e)n.

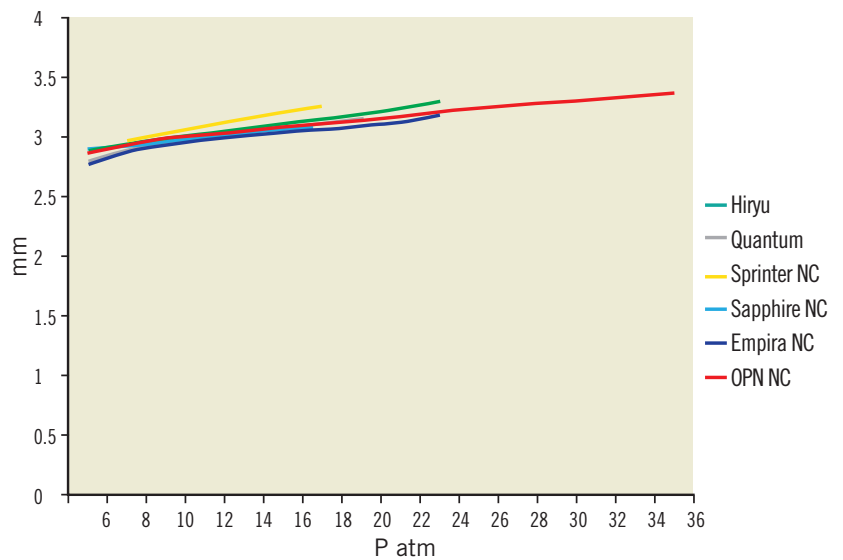

Figure 2. Comparison among different NC balloons' compliance $3.0 \mathrm{~mm}$ diameter: Hiryu ${ }^{\mathrm{TM}}$ (Terumo Medical, Tokyo, Japan), NC Quantum Apex ${ }^{\mathrm{TM}}$ (Boston Scientific, Marlborough, MA, USA), NC Sprinter ${ }^{\circledR} R X$ (Medtronic, Minneapolis, MN, USA), Sapphire NC TM (OrbusNeich, Wanchai, Hong Kong, China), Empira ${ }^{\mathrm{TM}}$ NC (Cordis, Johnson \& Johnson, Warren, NJ, USA), OPN NC ${ }^{\circledR}$ (SIS Medical AG, Winterthur, Switzerland). Please note that the OPN NC balloon is the only commercially available NC PTCA balloon catheter with a satisfactory compliance up to $35 \mathrm{~atm}$.

Table 1. OPN balloon compliance chart.

\begin{tabular}{|c|c|c|c|c|c|}
\hline $\begin{array}{c}\text { PRESSURE } \\
(\mathbf{a t m})\end{array}$ & $\begin{array}{c}\text { OPN NC } \\
\mathbf{2 . 0}\end{array}$ & $\begin{array}{c}\text { OPN NC } \\
\mathbf{2 . 5}\end{array}$ & $\begin{array}{c}\text { OPN NC } \\
\mathbf{3 . 0}\end{array}$ & $\begin{array}{c}\text { OPN NC } \\
\mathbf{3 . 5}\end{array}$ & $\begin{array}{c}\text { OPN NC } \\
\mathbf{4 . 0}\end{array}$ \\
\hline 10 & 2.0 & 2.5 & 3.0 & 3.5 & 4.0 \\
\hline 20 & 2.1 & 2.6 & 3.14 & 3.67 & 4.19 \\
\hline 30 & 2.18 & 2.7 & 3.29 & 3.85 & 4.37 \\
\hline 35 & 2.2 & 2.77 & 3.36 & 3.91 & 4.41 \\
\hline
\end{tabular}

\section{INTERVENTIONAL PROCEDURE}

PCI was routinely performed with standard techniques via the femoral or radial approach using 6 or 7 Fr guiding catheters. Patients not preloaded with oral aspirin and/or clopidogrel received a loading dose of intravenous aspirin (500 mg) and clopidogrel (600 mg) or prasugrel $(60 \mathrm{mg})$ as standard practice in our catheterisation laboratory. Intravenous heparin (70 IU/kg body weight) was administered before the procedure with subsequent boluses aimed at achieving an activated clotting time (ACT) of between 250 and $300 \mathrm{sec}$. The use of GP IIb/IIIa inhibitors was minimised and left to the discretion of the operator. In all cases, lesion predilatation was performed with a low-profile normal balloon slightly undersized according to conventional angiographic criteria. In case of incomplete balloon expansion with visible indentation at inflation pressures close to the rated burst pressure the lesion was approached using a conventional $\mathrm{NC}$ balloon inflated at least at the rated burst pressure and often higher. If this step also failed to provide an adequate luminal gain because of residual underexpansion of the balloon, the OPN NC balloon (with the same diameter as the NC balloon) was inflated up to $40 \mathrm{~atm}$. Finally, all lesions were treated with DES optimised by NC balloon inflation when needed. In case of stent underexpansion with residual stenosis $>40 \%$ assessed by angiography, the OPN $\mathrm{NC}$ balloon (with the same diameter as the NC balloon used) was inflated up to $40 \mathrm{~atm}$ for stent optimisation.

\section{ANGIOGRAPHIC ANALYSIS}

As is routine in our centre, standard image acquisition of the treated stenosis was performed using two or more angiographic projections after intracoronary nitroglycerine $100-200 \mathrm{mcg}$ or isosorbide dinitrate 2-3 mg to provide maximum coronary dilation. We identified the projection where the lesion was best visualised and appeared more severe with no overlapping and minimal foreshortening. We filmed the lesion in this view during all balloon inflations and for final angiography. Quantitative coronary angiography (QCA) was performed using a computer-based QCA system (Medis, Leiden, The Netherlands) with the dye-filled guiding catheter used for calibration. MLD and \%DS were measured at baseline, after conventional NC balloon dilatation, and after OPN NC balloon dilatation. The interpolated reference diameter was considered as reference segment diameter. Lesion length was defined as the distance from the proximal to the distal shoulder of the lesion. Acute gain after conventional NC balloon was defined as MLD (mm) post NC conventional balloon - baseline MLD (mm). Acute gain after OPN $\mathrm{NC}$ balloon was defined as MLD post OPN NC balloon (mm) baseline MLD (mm). Incremental gain after OPN NC balloon was defined as MLD post OPN NC balloon (mm) - MLD post conventional $\mathrm{NC}$ balloon $(\mathrm{mm})$.

\section{FOLLOW-UP}

Clinical events were evaluated post-procedure, during hospitalisation and at 30-day follow-up.

\section{DEFINITIONS}

Angiographic success was defined as the achievement of residual angiographic stenosis $<30 \%$ assessed by visual estimation with TIMI 3 flow. Procedural success was defined as the achievement 
of angiographic success without any MACE, defined as death, myocardial infarction and repeat revascularisation (coronary artery bypass graft $[\mathrm{CABG}]$ or percutaneous transluminal coronary angioplasty [PTCA]). Twelve-lead electrocardiograms were recorded before, immediately after the procedure and at hospital discharge. In-hospital MACE was defined as any MACE occurring during hospitalisation for the index procedure. Follow-up MACE was defined as myocardial infarction, death or target lesion revascularisation (any repeat PCI or CABG at the lesion site) occurring during the follow-up period. Postprocedural access-site "bleeding" was defined according to TIMI criteria ${ }^{11}$, and haematoma was defined as an arterial puncture site swelling $>5 \mathrm{~cm}$.

\section{STATISTICAL ANALYSIS}

Continuous variables were expressed as mean \pm standard deviation, while categorical variables were presented as numbers with percentage. Continuous variables were compared using the paired Student's t-test. Categorical variables were compared using the chisquare test. A p-value $<0.05$ was considered statistically significant.

\section{Results}

Patient and lesion characteristics are shown in Table 2 and Table 3, respectively. The average age was $69.4 \pm 9.5$ years with a prevalence of males $(80.2 \%)$ and standard distribution of risk factors (hypertension $82.4 \%$, hypercholesterolaemia $69.2 \%$, diabetes $46.1 \%$, previous or current smoking $65.9 \%$ ). Out of the 91 lesions, 54 were heavily calcified or fibrotic lesions $(59.3 \%)$ in previously untreated vessels, and seven were ISR (7.7\%) in which conventional NC balloons did not expand during predilatation. In the remaining 30 cases the OPN NC balloons were used after stent deployment for stent optimisation (33\%). Procedural characteristics are shown in Table 3. Predilatation using a semi-compliant balloon was performed in all cases and was then followed by a successive dilatation

\section{Table 2. Baseline patient characteristics.}

\begin{tabular}{|l|c|}
\hline Number of patients & 91 \\
\hline Sex (male/female) & $73 / 18(80.2 \% / 19.8 \%)$ \\
\hline Age & $69.4 \pm 9.5$ \\
\hline Risk factors & $75(82.4 \%)$ \\
\hline Hypertension & $63(69.2 \%)$ \\
\hline Hypercholesterolaemia & $60(65.9 \%)$ \\
\hline Smoking & $52(57.1 \%)$ \\
\hline Family history & $42(46.1 \%)$ \\
\hline Diabetes & $35(38.4 \%)$ \\
\hline Prior MI & $21(23 \%)$ \\
\hline Prior CABG & $19(28.9 \%)$ \\
\hline Renal failure & $52.6 \pm 12.9$ \\
\hline LVEF (\%) & $76(83.6 \%)$ \\
\hline Clinical presentation & $11(12 \%)$ \\
\hline Stable angina & $4(4.4 \%)$ \\
\hline Unstable angina & \\
\hline NSTEMI & $\begin{array}{l}\text { CABG: coronary artery bypass graft; LVEF: left ventricular ejection } \\
\text { fraction; MI: myocardial infarction; } \\
\text { myocardial infarction }\end{array}$ \\
\hline
\end{tabular}

Table 3. Lesion and procedural characteristics.

\begin{tabular}{|l|c|}
\hline Number of treated lesions & 91 \\
\hline Vessel & $2(2.2 \%)$ \\
\hline Left main & $45(49.4 \%)$ \\
\hline LAD & $15(16.5 \%)$ \\
\hline LCX & $26(28.6 \%)$ \\
\hline RCA & $3(3.3 \%)$ \\
\hline SVG & $43(47.2 \%)$ \\
\hline Multivessel disease & \\
\hline Lesion characteristics & $21 \pm 12$ \\
\hline Length (mm) & $38(41.7 \%)$ \\
\hline True bifurcation & $12(13.2 \%)$ \\
\hline Ostium involved & $37(40.6 \%)$ \\
\hline Calcific lesion & $17(18.7 \%)$ \\
\hline CTO & $30(33 \%)$ \\
\hline Optimisation after stenting & $7(7.7 \%)$ \\
\hline ISR & \\
\hline Balloon & $128 / 91(1.4)$ \\
\hline Number of NC balloon/lesion & $21.4 \pm 2.8$ \\
\hline Final NC balloon inflation (atm) & $2.6 \pm 0.6$ \\
\hline NC balloon mean diameter & $91 / 91(1.0)$ \\
\hline Number of OPN NC balloon/lesion & $37.2 \pm 2.7$ \\
\hline Final OPN NC balloon inflation (atm) & $2.8 \pm 0.4$ \\
\hline OPN NC balloon mean diameter & $124(1.35)$ \\
\hline Number of stent/lesion & $21(23.1 \%)$ \\
\hline IVUS guided & $10 \%)$ \\
\hline OCT guided & \\
\hline CTO: chronic total occlusion; ISR: in-stent restenosis; \\
\hline IVUS: intravascular ultrasound; LAD: left anterior descending artery; \\
LCX: left circumflex artery; NC: non-compliant; OCT: optical coherence \\
tomography. RCA: right coronary artery; SVG: saphenous vein graft \\
\hline
\end{tabular}

using a conventional $\mathrm{NC}$ balloon, sized according to conventional angiographic criteria and inflated up to the rated burst pressure or slightly higher. A total of $128 \mathrm{NC}$ balloons were used (1.4 per lesion). In all cases, the dilatation performed with the conventional $\mathrm{NC}$ balloon failed to achieve an adequate balloon expansion and luminal gain. After the failed attempt the OPN NC balloon with the same diameter as the conventional $\mathrm{NC}$ balloon was inflated up to $40 \mathrm{~atm}$. A total of 91 OPN NC balloons were used (one per lesion). Angiographic success was achieved in 84 lesions (92.3\%). In three severely calcified subocclusive stenoses (3.3\%) the OPN $\mathrm{NC}$ balloon failed to cross, while in two cases, despite successful crossing, the OPN NC failed to achieve an adequate luminal gain $(2.2 \%)$. All five lesions were finally successfully treated with rotational atherectomy (5.5\%). The remaining two cases were undilatable lesions in small and tortuous vessels for which both rotational atherectomy and excimer laser therapy were deemed unsafe $(2.2 \%)$. GP IIb/IIIa inhibitors were used in six patients (6.6\%).

\section{ANGIOGRAPHIC RESULTS}

QCA analysis is shown in Table 4. Both MLD and acute gain were significantly greater and \%DS was significantly lower post OPN NC balloon inflation compared with post plain NC balloon inflation $(1.7 \pm 0.8 \mathrm{~mm}$ vs. $2.4 \pm 0.9 \mathrm{~mm}, \mathrm{p}<0.001 ; 41.1 \pm 15.8 \%$ 
Table 4. QCA analysis.

\begin{tabular}{|c|c|c|c|c|}
\hline & Baseline & Post NC balloon & Post OPN NC balloon & $p$-value \\
\hline $\mathrm{RD}(\mathrm{mm})$ & $2.6 \pm 0.8$ & - & - & \multirow{2}{*}{$<0.001$} \\
\hline MLD & $0.7 \pm 0.3$ & $1.7 \pm 0.8$ & $2.4 \pm 0.9$ & \\
\hline$\%$ DS & $73.6 \pm 9.9$ & $41.1 \pm 15.8$ & $20.2 \pm 14.9$ & \multirow{2}{*}{$<0.001$} \\
\hline Lesion length (mm) & $11.9 \pm 6.4$ & - & - & \\
\hline Acute gain $(\mathrm{mm})$ & - & $1.1 \pm 0.7$ & $1.9 \pm 0.8$ & \multirow{2}{*}{$<0.001$} \\
\hline Incremental gain (mm) & - & - & $0.8 \pm 0.4$ & \\
\hline
\end{tabular}

vs. $20.2 \pm 14.9 \%, \mathrm{p}<0.001)$. These results were achieved with no increase in balloon size but with a higher inflation pressure (37.2 \pm 2.7 atm vs. $21.4 \pm 2.8 \mathrm{~atm}, \mathrm{p}<0.001)$ (Figure 3).

\section{PROCEDURAL AND CLINICAL OUTCOME}

Angiographic and technical success with OPN NC balloons was achieved in 84 lesions (92.3\%). In the remaining seven cases $(7.7 \%)$, five lesions were successfully treated with rotational atherectomy $(5.5 \%)$, while the remaining two cases were undilatable lesions for which both rotational atherectomy and excimer laser therapy were not attempted because of small vessel size and excessive tortuosity $(2.2 \%)$. No coronary perforation or balloon rupture and ST change were reported after the procedure. No in-hospital or 30-day MACE was reported. No major postprocedural bleeding was reported. Haematoma of the access site occurred in five patients treated by the transfemoral approach $(5.5 \%)$.

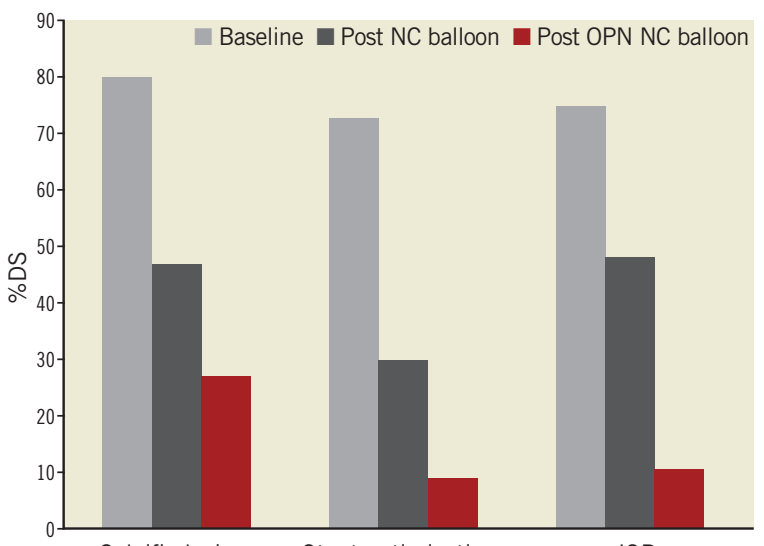

Calcific lesions Stent optimisation

ISR

Figure 3. Decrease in \% of diameter stenosis (DS) in calcific lesions (Group A), stent optimisation (Group B) and in-stent restenosis (ISR) (Group C). The incremental gain offered by the OPN NC balloon was sufficient to achieve angiographic success in all three subgroups

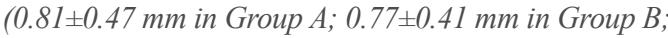
$1.34 \pm 0.31 \mathrm{~mm}$ in Group C).

\section{Discussion}

In our registry we tested the safety and efficacy of the OPN NC super high-pressure balloon in a consecutive series of truly heavily resistant coronary stenoses non-responsive to plain NC balloon dilatation. With the OPN NC balloon we were able to achieve a more than acceptable post-dilatation luminal gain in $92 \%$ of the cases without the need of additional expensive devices.

The mechanical properties of the arterial wall are critically dependent on the thickness, distribution and characteristics of the intimal plaque ${ }^{12}$. Thick neointimal hyperplasia and severe coronary calcification contribute to increase the hoop stress to the point that even high-pressure non-compliant balloons might be insufficient to overcome the hoop stress and induce a satisfactory dilatation.

During dilatation of resistant coronary lesions, the non-uniform balloon expansion with the consequent overexpansion of the more compliant segment (the so-called "dog-boning" effect) may lead to an increased risk of vessel wall damage, including edge dissections and coronary perforation. A variety of devices and strategies has been developed to overcome this limitation. Cutting balloons have been designed to relieve the vessel hoop stress by creating controlled small incisions in the vessel wall: they present the practical advantage that they do not move during inflation due to the stabilising effect of the blades. Cutting balloons present several advantages for the treatment of severe calcified lesions, allowing a larger luminal gain at lower pressure compared to balloon angioplasty alone and preventing late recoil due to the incisions created by the blades ${ }^{7,13}$. The lack of clinical benefit observed in early studies of cutting balloon vs. conventional balloon angioplasty in de novo lesions has created scepticism on the potential mechanical usefulness offered by a focal concentration of force on the intimal plaque.

Mehran et $\mathrm{al}^{14}$ showed that, when treating in-stent restenosis with balloon angioplasty, luminal gain is achieved by a combination of additional stent expansion and neointimal tissue compression through the stent, resulting in a displacement through the stent struts and compression of neointimal tissue. Although satisfactory initial clinical and angiographic results were obtained with balloon angioplasty, a significant early lumen loss was also observed shortly after in-stent restenosis treatment due to recoil and re-intrusion of neointimal tissue in the lumen ${ }^{15}$. This early phenomenon possibly influences the long-term outcome after balloon angioplasty for instent restenosis, affected by a high re-restenosis rate ${ }^{16,17}$. Despite these findings, several randomised studies showed no real advantage of CB over PTCA with a conventional balloon, and both the rigidity and the risk of balloon entrapment can limit their routine use during treatment of heavily calcified coronary lesions. 
Modification of the vessel wall using rotational atherectomy and excimer laser therapy improves vessel wall compliance, thus facilitating uniform stent expansion.

Excimer laser therapy is based on the principle of photoablation, converting occlusive material into microbubbles which are immediately dissolved in the blood ${ }^{18}$. Its successful use during treatment of resistant coronary lesions has been described previously ${ }^{19}$.

Rotational atherectomy is a technique in which a small grinder is inserted into the coronary arteries to ablate the plaque. Specifically, it is effective in the treatment of calcified lesions because of its differential cutting mechanism, a phenomenon by which soft tissues (such as the normal arterial wall) are deflected so that the grinder will not contact them during high-speed rotation, while hard calcified plaques are not deflected and can be ablated by the grinder ${ }^{20}$. Upsizing the burr might enable better lesion modification, resulting in greater stent expansion and strut apposition. It is, however, unknown whether routine usage of aggressive rotational atherectomy is superior to conventional balloon dilatation as a means of lesion modification, followed by DES implantation, because of the lack of systemic long-term results of such a strategy ${ }^{21,22}$.

Despite the fact that the majority of resistant coronary lesions can be treated with balloon dilatation and stent implantation alone ${ }^{23}$, the rigid obstacle imposed by calcium or thick neointimal hyperplasia might prevent an optimal balloon expansion and symmetric stent deployment, thus resulting in a gross malapposition of the stent struts. The importance of this is indirectly confirmed by findings from the e-Cypher registry correlating calcific lesions with the future occurrence of stent thrombosis ${ }^{24}$. The real clinical consequence of strut malapposition is still a matter of debate but certainly it may impinge on the elution properties of DES, increase the activation of fibrin and platelets, and thus result in accelerated intimal hyperplasia or stent thrombosis. Although the use of dedicated techniques such as rotational atherectomy might certainly improve procedural success in the treatment of resistant coronary lesions, the complexity, the cost and the need of dedicated operators have hindered their widespread application.

Conversely, the OPN NC super high-pressure balloon is a plain rapid exchange PTCA catheter which can be attempted easily in case of the failure of conventional balloons ${ }^{4}$. Thanks to its twin-layer technology, it allows the use of very high-pressure inflations, ensuring uniform expansion over a wide range of pressures and reducing the risk of vessel damage ${ }^{25}$. In our registry we found a significant increase of MLD and acute luminal gain after OPN NC balloon dilatation compared with plain NC balloon inflation. Moreover, as a consequence of the OPN NC's uniform expansion we had no vessel rupture despite the use of very high-pressure inflations.

\section{Limitations}

The main limitation of the OPN NC balloon is its high profile which, together with the stiffness of the twin-layer technology, in the vast majority of cases undermines any attempt to recross when inflated. The balloon does not refold well, and after inflation it is very difficult to use it again (for instance for both pre- and post-dilatation). An independent core lab and multiple observer QCA analysis would have improved reliability of data. Moreover, our results come from a small sample, retrospective and non-randomised comparison which is certainly susceptible to selection bias.

\section{Conclusions}

When conventional NC balloons fail, OPN NC super high-pressure balloons can provide an effective strategy for treatment of severely calcified coronary lesions. Moreover, our data suggest that the unique twin-layer technology offered by the OPN NC balloon achieves uniform balloon expansion, reducing balloon rupture, vessel damage and coronary perforation.

\section{Impact on daily practice}

Heavy calcified coronary artery lesions impose a rigid obstacle to optimal balloon expansion and symmetric stent deployment resulting in an increased risk of in-stent restenosis and thrombosis. Certainly, rotational atherectomy is the gold standard treatment for calcific lesions, but its use in daily practice is limited by the cost and the need for dedicated operators. Conversely, the OPN NC high-pressure balloon is a plain rapid exchange PTCA catheter which can be easily used in case of the failure of conventional balloons, providing a safe and easy alternative strategy in case of failure of conventional NC balloon dilatation.

\section{Conflict of interest statement}

The authors have no conflicts of interest to declare.

\section{References}

1. Fujii K, Carlier SG, Mintz GS, Yang YM, Moussa I, Weisz G, Dangas G, Mehran R, Lansky AJ, Kreps EM, Collins M, Stone GW, Moses JW, Leon MB. Stent underexpansion and residual reference segment stenosis are related to stent thrombosis after sirolimuseluting stent implantation: an intravascular ultrasound study. $\mathrm{J} \mathrm{Am}$ Coll Cardiol. 2005;45:995-8.

2. Hoffmann R, Mintz GS, Popma JJ, Satler LF, Kent KM, Pichard AD, Leon MB. Treatment of calcified coronary lesions with Palmaz-Schatz stents. An intravascular ultrasound study. Eur Heart J. 1998;19:1224-31.

3. Hoffmann R, Mintz GS, Kent KM, Pichard AD, Satler LF, Popma JJ, Hong MK, Laird JR, Leon MB. Comparative early and nine-month results of rotational atherectomy, stents, and the combination of both for calcified lesions in large coronary arteries. Am J Cardiol. 1998;81:552-7.

4. Raja Y, Routledge HC, Doshi SN. A noncompliant, high pressure balloon to manage undilatable coronary lesions. Catheter Cardiovasc Interv. 2010;75:1067-73.

5. Karvouni E, Stankovic G, Albiero R, Takagi T, Corvaja N, Vaghetti M, Di Mario C, Colombo A. Cutting balloon angioplasty for treatment of calcified coronary lesions. Catheter Cardiovasc Interv. 2001;54:473-81. 
6. Fonseca A, Costa Jde R Jr, Abizaid A, Feres F, Abizaid AS, Costa R, Staico R, Mattos LA, Sousa AG, Grube E, Sousa JE. Intravascular ultrasound assessment of the novel AngioSculpt scoring balloon catheter for the treatment of complex coronary lesions. J Invasive Cardiol. 2008;20:21-7.

7. Secco GG, Foin N, Viceconte N, Borgia F, De Luca G, Di Mario C. Optical coherence tomography for guidance of treatment of in-stent restenosis with cutting balloons. EuroIntervention. 2011;7:828-34.

8. Giugliano GR, Cox N, Popma J. Cutting balloon entrapment during treatment of in-stent restenosis: an unusual complication and its management. J Invasive Cardiol. 2005;17:168-70.

9. Sánchez-Recalde A, Galeote G, Martín-Reyes R, Moreno R. AngioSculpt PTCA balloon entrapment during dilatation of a heavily calcified lesion. Rev Esp Cardiol. 2008;61:1361-3.

10. Cohen BM, Weber VJ, Relsman M, Casale A, Dorros G. Coronary perforation complicating rotational ablation: the U.S. multicenter experience. Cathet Cardiovasc Diagn. 1996;Suppl 3:55-9.

11. Cannon CP, Battler A, Brindis RG, Cox JL, Ellis SG, Every NR, Flaherty JT, Harrington RA, Krumholz HM, Simoons ML, Van De Werf FJ, Weintraub WS, Mitchell KR, Morrisson SL, Brindis RG, Anderson HV, Cannom DS, Chitwood WR, Cigarroa JE, CollinsNakai RL, Ellis SG, Gibbons RJ, Grover FL, Heidenreich PA, Khandheria BK, Knoebel SB, Krumholz HL, Malenka DJ, Mark DB, Mckay CR, Passamani ER, Radford MJ, Riner RN, Schwartz JB, Shaw RE, Shemin RJ, Van Fossen DB, Verrier ED, Watkins MW, Phoubandith DR, Furnelli T. American College of Cardiology key data elements and definitions for measuring the clinical management and outcomes of patients with acute coronary syndromes. A report of the American College of Cardiology Task Force on Clinical Data Standards (Acute Coronary Syndromes Writing Committee). J Am Coll Cardiol. 2001;38:2114-30.

12. Vito RP, Dixon SA. Blood vessel constitutive models-1995-2002. Annu Rev Biomed Eng. 2003;5:413-39.

13. Lee MS, Singh V, Nero TJ, Wilentz JR. Cutting balloon angioplasty. J Invasive Cardiol. 2002;14:552-6.

14. Mehran R, Mintz GS, Popma JJ, Pichard AD, Satler LF, Kent KM, Griffin J, Leon MB. Mechanisms and results of balloon angioplasty for the treatment of in-stent restenosis. Am J Cardiol. 1996;78:618-22.

15. Shiran A, Mintz GS, Waksman R, Mehran R, Abizaid A, Kent KM, Pichard AD, Satler LF, Popma JJ, Leon MB. Early lumen loss after treatment of in-stent restenosis: an intravascular ultrasound study. Circulation. 1998;98:200-3.
16. Mehran R, Dangas G, Abizaid AS, Mintz GS, Lansky AJ, Satler LF, Pichard AD, Kent KM, Stone GW, Leon MB. Angiographic patterns of in-stent restenosis: classification and implications for long-term outcome. Circulation. 1999;100:1872-8.

17. Alfonso F, Cequier A, Angel J, Martí V, Zueco J, Bethencourt A, Mantilla R, López-Minguez JR, Gómez-Recio M, Morís C, Perez-Vizcayno MJ, Fernández C, Macaya C, SeabraGomes R; Restenosis Intra-stent Balloon angioplasty versus elective Stenting (RIBS) Investigators. Value of the American College of Cardiology/American Heart Association angiographic classification of coronary lesion morphology in patients with in-stent restenosis. Insights from the Restenosis Intra-stent Balloon angioplasty versus elective Stenting (RIBS) randomized trial. Am Heart J. 2006;151:681.e1-681.e9.

18. Schwarzwalder U, Zeller T. Debulking procedures: potential device specific indications. Tech Vasc Interv Radiol. 2010;13: 43-53.

19. Ben-Dor I, Maluenda G, Pichard AD, Satler LF, Gallino R, Lindsay J, Waksma R. The use of excimer laser for complex coronary artery lesions. Cardiovasc Revasc Med. 2011;12:69.e1-8.

20. Kim MH, Kim HJ, Kim NN, Yoon HS, Ahn SH. A rotational ablation tool for calcified atherosclerotic plaque removal. Biomed Microdevices. 2011;13:963-71.

21. Tanigawa J, Barlis P, Di Mario C. Heavily calcified coronary lesions preclude strut apposition despite high pressure balloon dilatation and rotational atherectomy: in-vivo demonstration with optical coherence tomography. Circ J. 2008;72:157-60.

22. Moussa I, Di Mario C, Moses J, Reimers B, Di Francesco L, Martini G, Tobis J, Colombo A. Coronary stenting after rotational atherectomy in calcified and complex lesions. Angiographic and clinical follow-up results. Circulation. 1997;96:128-36.

23. Clavijo LC, Steinberg DH, Torguson R, Kuchulakanti PK, Chu WW, Fournadjiev J, Satler LF, Kent KM, Suddath WO, Waksman R, Pichard AD. Sirolimus-eluting stents and calcified coronary lesions: clinical outcomes of patients treated with and without rotational atherectomy. Catheter Cardiovasc Interv. 2006;68:873-8

24. Urban P, Gershlick AH, Guagliumi G, Guyon P, Lotan C, Schofer J, Seth A, Sousa JE, Wijns W, Berge C, Deme M, Stoll HP; e-Cypher Investigators. Safety of coronary sirolimus-eluting stents in daily clinical practice: one-year follow-up of the e-Cypher registry. Circulation. 2006;113:1434-41.

25. Díaz JF, Gómez-Menchero A, Cardenal R, SánchezGonzález C, Sanghvi A. Extremely high-pressure dilation with a new noncompliant balloon. Tex Heart Inst J. 2012;39:635-8. 